\title{
Farmers' Adoption of Climate Smart Practices for Increased Productivity in Nigeria
}

\author{
B. E. Fawole and S. A. Aderinoye-Abdulwahab
}

\section{Contents}

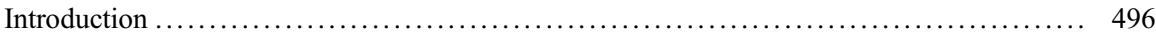

Adoption Theory as a Conceptual Framework ................................. 497

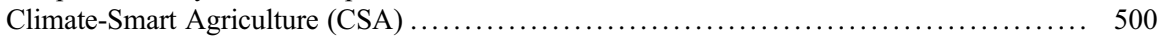

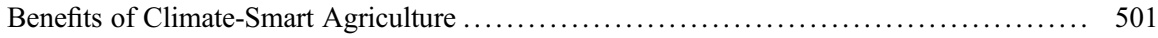

Adoption of Climate-Smart Agricultural Practices by Rural Farmers in Nigeria ........... 503

Challenges of Climate Smart Agriculture Practices .............................. 504

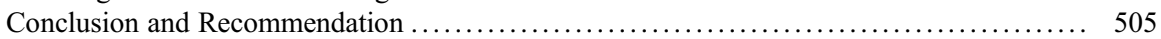

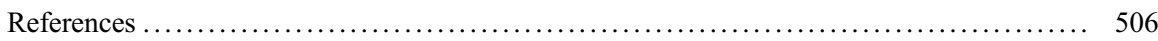

\section{Abstract}

In a bid to reinforce the efforts of agricultural professionals within the domain of climate change studies and with particular emphasis on rural farmers in Nigeria, this chapter explores the mechanics for adoption of climate smart agricultural practices among rural farmers for an increased agricultural productivity. ClimateSmart Agriculture (CSA) is paramount to the success of farming activities today in the face of the menace of the impact of climate change. Climate Smart Agricultural

This chapter was previously published non-open access with exclusive rights reserved by the Publisher. It has been changed retrospectively to open access under a CC BY 4.0 license and the copyright holder is "The Author(s)". For further details, please see the license information at the end of the chapter.

B. E. Fawole

Department of Agricultural Extension and Rural Development,

Federal University, Dutsinma, Nigeria

e-mail: bfawole@fudutsinma.edu.ng

S. A. Aderinoye-Abdulwahab ( $\square)$

Department of Agricultural Extension and Rural Development,

Faculty of Agriculture, University of Ilorin, Ilorin, Nigeria

e-mail: aderinoye.as@unilorin.edu.ng 
Practice (CSAP) is one of the major keys that agricultural development approaches aimed at; to sustainably increase productivity and resilience, while also reducing the effects; as well as removing emissions of greenhouse gases. It is pertinent to note that most of the CSAPs adopted by the rural farmers in this study are conservation agriculture, use of organic manure, crop diversification, use of wetland (Fadama), planting of drought tolerant crops, relocation from climate risk zones, prayers for God's intervention, and improvement on farmers' management skills. This study divulged and showcased the import of CSAP in boosting agricultural yield and also highlights the bottlenecks inhibiting agricultural farming practices such as lack of practical understanding of the approach, inadequate data and information, lack of suitable tools at local and national levels, supportive and enabling policy frameworks, and socioeconomic constraints at the farm level. The study concluded by recommending an aggressive awareness and mobilization campaign to boost the adoption of CSAPs in Nigeria.

\section{Keywords}

Rural areas $\cdot$ Agricultural risks and productivity $\cdot$ Policy $\cdot$ Relocation · Greenhouse gases

\section{Introduction}

Agriculture plays a huge role in Africa's economy with about $70 \%$ of the continent's population practicing subsistence farming for their livelihood while they equally live in the rural areas. Hence, the significance of this sector in providing employment and motivating economic growth in a developing nation such as Nigeria cannot be undermined. Agriculture mainly hinges on environmental factors and any prolonged variations in average weather conditions can have significant impacts on production. Additionally; agriculture as practiced in the continent, is highly characterized by land tenure insecurity which continues to hamper agricultural growth for millions of smallholder farmers; while poor soil fertility, degraded ecosystems and climate variability are among other problems associated with agriculture in Africa (USAID 2016). Climate change adaptation has to do with any spontaneous and/or premeditated action/mechanism adopted to deal/cope with the impacts of, or reduce vulnerability to, a changing climate.

Adaptation should address immediate problems and anticipate future changes in order to mitigate adverse effects. The strategies applied in adaptation can be preventive or reactive while all the methods taken should aim at enhancing resilience and reducing vulnerability (IPCC 2012). There is a dire need to deliberately advance a rigorous implementation of the identified strategies for adaptation and mitigation. This is in a bid to minimize the effects of climate change in order that development in agriculture can be encouraged. Mitigation refers to measures that may either reduce the increase in greenhouse gases (GHGs) emissions or increase terrestrial storage of carbon, while adaptation refers to all the responses to climate change that may be 
used to reduce vulnerability (Ifeanyi-obi and Nnadi 2014). Indeed, there have been deliberate efforts by Heads of States to integrate approaches that have been employed to solve the impacts of climate variability. Evidence is seen in the authorization of governments to support at least twenty-five million farming households to adopt Climate Smart Agriculture (CSA) by 2025. (African Climate Smart Agriculture Summit 2014).

The concept of CSA, which came into limelight in 2010, is defined as a form of agriculture that increases agricultural production and income; enhances adaptation and build resilience to climate change impact. CSA also helps to reduce the emissions due to Greenhouse gases (GHGs) and enhances the attainment of global food safety (World Bank 2010; FAO 2014). Climate-smart ideas include activities that would ensure minimum tillage; application of organic agricultural practices rather than inorganic methods that would further deplete the soil in the long term; crop rotation and mulching to reduce evapotranspiration; and composting and planting of legumes and cover crops which assist in moderating the long-term effects of climate change by giving an enduring environmental strength to the soil (Olorunfemi et al. 2019; Ojoko et al. 2017). This chapter therefore sets to explore the CSAPs available, the benefits accruable from practicing CSA in order to increase productivity and the challenges hindering their adoption in Nigeria.

\section{Adoption Theory as a Conceptual Framework}

The choice of adopting a technology is preceded by a number of certain mental processes which include: Awareness, Interest, Evaluation, Trial, and Adoption. According to Ekong (2010), adoption process is the mental procedure from the first instance of learning of an idea/technology to the final stage of taking a decision to use it. The farmer's choice to accept or reject a technology is based on their perception of those stages earlier mentioned. This implies that a farmer can only decide to use a technology only if he was aware of it; develops interest in it; and possibly, after he must have tried it and becomes convinced that the technology is beneficial to him.

Awareness stage: At this first stage, the farmer is barely conversant with the existence of an innovation; it could be that he only became cognizant of the technology and may be deficient in the technicalities such as how to use the innovation, the cost; as well as the benefits of the innovation. The farmer may learn of the existence of the innovation through friends, relatives, mass media, extension agents or local cooperative organization. After being aware of the innovation, the farmer might crave for more information. He may want to understand how the invention works and also the benefits and usefulness. Consequently, the farmer can take the next step of making deep inquiries in order to access adequate information that would help him in reaching a decision.

Interest stage: during this second stage the farmer asks for detailed information concerning the technology. It is only normal that the farmer relies partly on their source (through which they became aware) of information to deepen their 
knowledge about it. The farmer can also search for better understanding from other sources which hopefully spurs them to become interested in the technology. This makes the farmer to develop interest by asking further questions and collecting information about the new idea or new product to assess its potentialities. These line of questioning can make the farmer to become curious and begin to wonder how much he can benefit should he decide to try the idea/technology.

Evaluation stage: this is the stage where the farmer mentally appraises the applicability of the technology in light of the solution to his own circumstances. The farmer makes a mental assessment by asking several questions such as: Is it/this possible? Who do I know that has done it? What was their outcome? Can I also do it? What happened the last time someone tried it? The responses to these questions and many more that the farmer might have mentally asked would be the determinant of whether he would go ahead to try it or not? If the evaluation produces a negative result, the farmer could stop showing interest in the innovation and may eventually reject it. However, if the responses he got from his mental assessment were favorable, he may then be set to try the innovation practically.

Trial stage: this is the stage where the farmer essentially implements or applies the innovation on a small scale under his personal circumstances and managerial competence. The farmer could entirely handle the trial stage all alone or they may seek the help of change agents and sales promoters. In this stage, the farmer raises the question: how am I supposed to do it? The farmer uses the innovation on a trial/ experimental basis on a portion or segment of their farm. The result, positive or negative, would then determine whether the farmer would take or discard the technology.

Adoption stage: The final stage of adoption is when the farmer eventually approves the innovation and has decided to continue using it on a full scale. In this stage, the farmer extends the use of the technology to their whole plots of land. Adoption involves an enduring acceptance and repeated utilization of the technology with the hope that it will help to ease a difficult farm situation. This suggests that a farmer may stop or discontinue the use of such innovation if subsequent outcomes do not prove reliable.

According to Adekoya and Tologbonse (2011), a prospective adopter has a number of characteristics to consider before concluding on whether to adopt an innovation or not. These characteristics are as listed:

1. Relative advantage: A technology must be perceived by the farmer as being better than the one currently in use. This can be measured in terms of profitability, low cost, and time saving ability. It could also be in terms of factors relating to social-prestige, convenience and satisfaction. The point that matters in this case is the discernment of advantage as perceived by the adopter.

2. Compatibility: This means that the new idea being professed is in consonance with the obtainable values, beliefs, ancient times experiences, and desires of prospective adopters. Hence, any innovation that does not conform with the standards of a community may not be accepted as fast as one that is compatible. 
3. Complexity: Some technologies are easily and willingly understood by majority of farmers in a community; whereas, others are more difficult and will take more time before they get accepted. Therefore, new ideas should be comparatively easy to comprehend and utilize when compared to existing ones as innovations that are simple to comprehend are accepted more rapidly.

4. Trial-ability: An innovation should normally be easily adaptable. What this implies is that, it will be possible to try a technology on a small scale. Any innovation that can be experimented on an installment arrangement will usually be more readily accepted than ideas that are not separable.

5. Observability: Farmers would normally want to be able to see the outcome of a new idea so that they could be able to discuss such results with fellow farmers. If outcomes of innovation are readily seen by farmers, then the chances of accepting such innovation become higher; whereas if there are no clear observable outcomes, it may be difficult for such ideas to be replicated and accepted.

6. Divisibility: It is a great idea for a technology to be divisible; this means that the innovation can be tested with small units before buying the whole gadget. Purchase of tractors or harvesters is a one-time major investment and part of it cannot be bought in order to try it out in phases. However, such technology can be hired for initial use before deciding on whether to purchase. A farmer can however, purchase and utilize a little quantity of improved seeds, fertilizer or herbicides.

7. Accessibility: Innovations that are easily available are more readily accepted. In this case, it is not advisable for a change agent to push for the distribution of farming inputs that farmers either cannot afford or for which infrastructure does not exist; as this would be an indication that the technology is not accessible.

8. Visibility: The results of the mode of operation of a given innovation should be easily seen, i.e., visible. A farmer can see a new spraying pump which has been made easier to handle; hence the likelihood of adoption becomes greater.

9. Cost: It has been consistently observed that innovation may not be easily adopted if it is perceived to be costlier than what currently exists; it thus goes to say that a new idea may have a relative advantage over an old one; but could meet up with resistance if the currently used practice is a lot cheaper. Generally, the higher the cost of an innovation, the more slowly it is adopted.

However, Rogers (2003) as cited by Ray (2011) argued that the choice to accept any part of an innovation depends on a procedure which is known as the innovation-decision process. Innovation-decision is conceptualized as having five stages and each of these stages can only take place after a period of time has passed. The stages are:

1. Knowledge stage: One is believed to have acquired knowledge the very moment a person is exposed to the technology reality and has achieved some perception of how such knowledge functions. The meaning of this is that knowledge role is primarily cognitive or knowing. People who acquire knowledge at an early stage; are regarded as generally more highly educated and are perceived as having higher social status; they are also more open to both mass media and interpersonal channels of communication, and they have more contact with change agents. 
2. Persuasion stage: One would have passed through the persuasion stage once a person forms an opinion about the new practice/idea; though this could only happen after going through several persuasive messages from development workers, sales promoters and close associates. The persuasion function is mainly connected or related to feelings and is thus; a stage laden with so much emotional attachment and/or factors. Hence, it is expected that the potential adopter may turn out to be more psychologically involved with the innovation and would actively seek information about the innovation/new practice. It is at this stage that the would-be adopter forms a good or bad attitude/impression towards the technology.

3. Decision stage: After being persuaded about the usefulness or benefits of an innovation, one would normally engage in activities which may culminate into either of two options; that is whether to take or discard the technology. Having observed that other people use the innovation, the potential adopter can choose to adopt or refuse the technology. People would adopt an innovation only if they are convinced of its usefulness and compatibility with their values and income.

4. Implementation stage: Implementation happen as soon as a person or other decision-making unit place a technology into use. At this stage the individual is generally concerned with where to get the innovation, how to use it and what operational problems will be faced and how those problems could be solved. Implementation might entail alteration in management of the venture and/or adjustment in the technology, to go well with the exact needs of the individual who accepts it.

5. Confirmation stage: This is the last stage in the innovation process when an individual finally accepts or rejects a new practice. Confirmation culminates in repeated use. Individuals seek reinforcement for the adoption decision they have made. The consequence is that they may exhibit continued adoption or exhibit discontinuance. Meanwhile, it is noteworthy to mention that the entire innovation-decision process has a sequence of options at every stage. For instance, in the knowledge function, the would-be adopter would have to decide on which of the innovation messages to attend to while they also have to make up their minds on which ones to disregard.

In the persuasion function, potential adopters must decide on the messages to seek out and the ones to ignore, whereas; in the decision function, the available options are different from what were obtainable in the previous stages. The decision stage presents with two possibilities which are either to accept or refuse a new idea. This decision involves an immediate consideration of having to try out an innovation or not to give it a try at all. Most farmers will accept an idea/technology only after trying it out; and it is after the trial that he can then determine its suitability.

\section{Climate-Smart Agriculture (CSA)}

CSA derives from an attribute in its terminology; that is, smart way of practicing agriculture. It is a form of agriculture that sustainably increases agricultural output and earnings; it enhances adaptation and aims to build resilience to the effect of 
climate change by reducing or eliminating Greenhouse Gases (GHGs) wherever possible, as well as advancing the attainment of global food safety (FAO 2014). CSA is mainly targeted at integrating the three broad areas of sustainable development which are the economic, social, and environmental components; by equally justifying food security, ecosystem management, and climate change problems.

Food security can be enhanced by maintaining an increasing agricultural production efficiency while the ecosystem can be more easily managed by adapting to, as well as building resilience to climate change. On the other hand, the climate change problems can largely be well mitigated by either working to lessen and/or eradicate greenhouse gases (GHG) emissions. However, CSA is never a pre-arranged condition, neither is it a given template that can be generally applied or practiced. Suffice to say that, it is a process that calls for site-specific assessments of the social, economic and ecological conditions to identify proper farming technologies that are appropriate in any given situation. It is important to note that a key component of CSA is the incorporated landscape method which suggests that the CSA practices that are being employed and/or applied in a given environment would follow the main beliefs of ecosystem management and sustainable land and water utilization. Climate-smart agriculture aims at supporting livelihoods at farm level by ensuring food security of smallholder farmers and helping to improve the management and utilization of natural resources. It also fosters the adoption of appropriate methods and skills for the production, processing and marketing of agricultural supplies. Whereas at the national level, CSA pursues legitimate and relevant technological and financial policies that would support nations to establish/entrench climate change adaptation into their agricultural sector. There is, at the national level, a considerable progressing efforts to promote CSA in Africa while ECOWAS also made efforts to support the mainstreaming of CSA into the ECOWAP/CAADP programs (ECOWAS 2015). In Nigeria specifically, there are research institutions and colleges owned by the Federal Government; who are working on CSA in order to render their own contribution to the fight against climate change related problems (FAO and ICRISAT 2019).

\section{Benefits of Climate-Smart Agriculture}

Climate-smart agriculture, as noted earlier, underscores the importance of building evidence to highlight practicable alternatives to the existing non-climate friendly approaches. It also encourages important enabling activities that can translate into better productivity and a friendlier environment. Through CSA, attention can be drawn to agricultural systems (crop, livestock, aquaculture, and agroforestry) that support the ecosystem services as this would enhance productivity, adaptation and mitigation; in a way that would encourage smart farming practices in order to reduce the effect of climate change (Adedeji et al. 2017). The CSA process offers stakeholders, such as farmers and other main players in the sector; the techniques and gadgets, as well as management and styles required to regulate more challenging and tougher production systems. 
The FAO, who has immensely contributed to the development of CSA in Africa, also trained numerous individuals on the CSA approach and have equally developed a program called Safe Approach to Fuel and Energy (SAFE) in northeast Nigeria (FAO 2019). The SAFE program is aimed at reducing the need for firewood and by extension, the release of greenhouse gas is further reduced. Among the documented efforts at reducing the impact of climate change is the Oxfam Nigeria and the European Union collaboration which designed a project named Pro-ResilienceAction (PROACT). PROACT started in Nigeria in 2016 with enhancement of food security as its purpose while helping farmers build enduring means of sustenance (FAO and ICRISAT 2019a). The project has Mubi South, Fufore, Song, and Guyuk local government areas (LGAs) of Adamawa State currently participating where certain relevant and appropriate climate-smart actions are being combined to support famers become more resilient. Some of the actions, which are rolled out in phases, are provision of farm inputs and training of farmers' groups.

In the four locations of Adamawa State (Mubi South, Fufore, Song, and Guyuk), inputs such as fertilizers and water pumps are supplied to farmers while extension workers are being trained on rural investments and formation of loan groups in order to enable them access flexible financing services (FAO and ICRISAT 2019a). So far, about 700 farmer groups (women constitute more than half of the population) have been provided with farm inputs. The scheme has documented some level of success as rice growers have seen a boost of almost 100 percent despite the dry season rice production (Adedeji et al. 2017). This was made possible due to the distribution of inputs such as improved seeds, water pumps, among others. The project did not only focus on input provision for farmers as about 70 government extension workers in Kebbi and Adamawa States have received training on better environment-friendly agricultural practices for improved cereals production (Adedeji et al. 2017; FAO and ICRISAT 2019a). Farmer Training Fields (FTF) were then established wherein the extension workers in PROACT Communities assist farmers in order to boost their capacity as well as support them to adopt the best practices that can improve their yields and productivity. It has been observed through field evidences that the FTF program has contributed to higher acceptance of CSAPs and this has translated into enhanced food safety and income for farmers (FAO and ICRISAT 2019a).

In the short run, the project aims to handover improved farming skills to farmers as well as equip them to plant 500,000 trees to battle desertification and climate change; while in the long run, it is expected that about 1,400 community investments and loan groups would have been established. Another observable CSA effort is seen in adoption of terracing as a climate-smart practice in the southern and northern parts of Borno State as a result of the rocky topography of the area (FAO and ICRISAT 2019b). A farmer, while confirming the use of terracing (even without the knowledge or advent of CSA) for more than forty years, confirmed that it helped to combat the effects of soil erosion by preserving moisture and crop nutrients on the farm.

The farmer affirmed a higher yield of sorghum and maize on terraced farms $(47 \%$ higher) when compared to non-terraced ones. Added to the advantage of terracing in the area is the assertion that farm events such as weeding and spraying are better managed on terraced farms while suggesting that farming in the entire southern part 
of Borno might have been very unprofitable if terracing was not being practiced (FAO and ICRISAT 2019b). Among the manifestation of the benefits of CSAPs is yet another evidence as provided by a farmer, in Potiskum LGA of Yobe State, who planted improved variety of millet (SOSAT) and got higher yields over and above the traditional variety (Gwagwa) that he had been planting previously (FAO and ICRISAT 2019c). Given the nature of local farmers, he initially resisted the new SOSAT variety as a replacement for his Gwagwa local variety. Hence, he intercropped SOSAT and Gwagwa millets with sorghum and cowpea as commonly practiced around Potiskum. This was done for 4 years while monitoring the variations in yield (FAO and ICRISAT 2019c). The farmer realized $550 \mathrm{~kg} / \mathrm{ha}$ from the traditional millet while SOSAT millet produced $900 \mathrm{~kg} / \mathrm{ha}$ in the first year. The following 2 years, on the same plots, but only intercropped with cowpea without sorghum, produced $350 \mathrm{~kg} / \mathrm{ha}$ of SOSAT over the traditional variety. The first year reflected a marked increase of $64 \%$ yield over the utilization of the traditional local variety while the next year produced yield increase of $88 \%$. This field experiment is yet another indication that climate-smart options, such as planting of improved varieties, could help enhance crop output and diversification which can also potentially increase profits of farmers (Tiamiyu et al. 2018b; FAO and ICRISAT 2019c).

\section{Adoption of Climate-Smart Agricultural Practices by Rural Farmers in Nigeria}

Smallholder farmers have, in the past, accidentally practiced CSA as part of their habitual farming system in Northern Nigeria (Fanen and Olalekan 2014). Similarly, it was also found in another study that the foremost strategy adopted by farmers to deal with climate change was to plant drought resistant varieties (Naswem et al. 2016). Other strategies used in mitigating the effect of climate change include: relocation from climate risk zones, prayers to God for divine intervention, multiple cropping, recycling of waste product, and improvement on farmers' management skills. According to Ojoko et al. (2017), the five most used CSAPs in Nigeria included conservation agriculture, application of organic manure, crop diversification, usage of wetland (Fadama), planting of drought tolerant crops, and agroforestry. Tiamiyu et al. (2017) in their study also reported similar findings where the adoption of CSAPs included climate smart approaches such as planting of drought tolerant and early maturing varieties, application of organic compost, use of cultural practices such as intercropping and crop rotation, composting rather than burning, and erection of terraces on sloppy/hilly farmland.

In other studies, Onyeneke et al. (2018) also reported that mixed farming, high yielding cultivars, agro-forestry, and other cultural practices such as mulching and zero tillage, as well as membership in development associations were the CSAPs adopted by the farmers in their study. Further evidence had showed that farmers in Nigeria have continued to adopt climate smart practices to mitigate the effect of climate change while simultaneously increasing productivity. For instance, female farmers adopted agro-forestry in derived savannah, guinea savannah, and rain forest, 
while the male farmers employed organic manure, zero tillage, and crop rotation in the same agro-ecological zones, respectively (Fapojuwo et al. 2018). However, it was observed that majority of farmers in the study never made use of the climate smart practices; hence low adoption rate because they were not even aware of the opportunities (Tiamiyu et al. 2018a). Nonetheless, planting of drought tolerant varieties and high yielding cultivars appear to be the most favored options accepted by farmers while only a few of the farmers used agro-forestry and integrated pest management as a smart way to curb the effect of climate change. Moreover, Adebayo and Ojogu (2019), in their study, had reported minimum or zero tillage, crop rotation, and other cultural practices such as mulching as the most favored CSAPs by farmers.

\section{Challenges of Climate Smart Agriculture Practices}

The adoption of CSAPs is linked to a myriad of impediments as there is an array of socio-economic and institutional complications. As usual, the need for significant upfront expenditures on the part of poor farmers, inadequate access to technical information that are potential solutions to farmers' problems, and the inability of farmers to convert the knowledge gained into practice; are part of the challenges associated with the adoption of CSAPs. Furthermore, some procedures that are climatically smart in nature and which are also associated to sustainable soil management may not be compatible with farmers' customs; thereby leading to nonadoption as previous studies have shown that, the onward dissemination of ideas may greatly rely on knowledge in combination with social activities that farmers may not be capable of performing (World Bank 2018).

It had been reported that lack of funding portends a huge bottleneck in the acceptance of CSAP in Northern Nigeria while farmers also have little or no knowledge of CSAP; in addition to a poor understanding of the application of some of those practices by extension workers who would normally be the ones to disseminate technology to the famers. Other challenges include a dearth of stakeholders such as nongovernmental organizations; who can drive the campaign for CSAPs in the region (Fanen and Olalekan 2014). Moreover, while dealing with climate change, desertification poses a big threat for people, farmers inclusive. Hence, the subtle drive for tree planting by a few organizations makes the situation more problematic; thereby suggesting a neglect of the root cause. The implication of this is that there is a real need for a holistic and aggressive mobilization for tree planting. Meanwhile, limited opportunities for local managers to partake in policy formulation/decisions at international and local levels is a further weakness in the effort to combat climate change impact by encouraging adoption of CSAPs. Other hindrances restraining farmers from using CSAPs include: lack of government's support, high cost of executing the practices, and insufficient training on the practices (Adebayo and Ojogu 2019). Specific challenges of CSA, according to Williams et al. (2015) are outlined: 
1. Lack of practical understanding of the approach: The need for a full comprehension of protocols surrounding the use of CSAPs is important in order for messages to be clearly communicated to farmers. Thus, the effort for scaling up initiatives will depend on the understanding of the CSA idea by relevant stakeholders.

2. Inadequate data and information: It is always a herculean task for African nations both at national and local levels to access and utilize suitable tools for climatic and landscape level data.

3. Inadequate investment in CSA: Again, it has been repeatedly found that investments required to scale up adaptation and resilience in agriculture is lacking right from national up to farm levels. The Africa's Infrastructure Diagnostic Report (Foster and Briceño-Garmendia 2010) also reported a deficit in social infrastructure such as road, transportation, communication, power and water; which are high requirements for the uptake of CSAP.

4. Socio-economic constraints: Access to productive resources like land, transportation and water, as well as human resources were the limitations at the farm level.

5. Inadequate women empowerment: Women who contribute significantly to food production in Africa are largely marginalized when it comes to access to and control over productive resources. For instance, it was found in a previous study carried out in northern Nigeria that women do not own and control productive assets such as land, crop inputs, livestock inputs, and capital (AderinoyeAbdulwahab et al. 2016) and that this makes them to be poorly empowered. It is noteworthy that such gender stereotypes relating to access to land rights, education, technologies, and credit; are among the countless stumbling blocks to women's effective contribution in the farming sector.

6. Poor funding and efficient risk-sharing schemes: Funding devices to support the uptake of CSAP are not yet popular in Africa nations. Whereas, huge investment is required for the transition to climate-smart agricultural development pathways as farmers continue to face the risk of accepting new technologies. Meanwhile, the benefits of the technologies often only come after several years/seasons of production, thus the realization of a wider coverage of CSAPs becomes problematic.

7. Difficulty in running trade-offs from the farmers' and policymakers' perspectives: The dissimilarity in objectives between farmer groups and policy makers continues to cause a difference of opinion in respect of priorities for resource management.

\section{Conclusion and Recommendation}

The adoption of smart agricultural practice is an integral part for increasing agricultural productivity as it enhances adaptation to climate change. It also helps to reduce greenhouse gases emissions while enhancing the attainment of food security. The popular CSAPs adopted by rural farmers in Nigeria are: conservation agriculture, adoption of organic compost, use of wetland (Fadama), utilization of drought 
tolerant crops, relocation from climate risk zones, and use of cultural and management practices such as mulching and prayers for divine intervention. The challenges militating against the adoption of CSAPs by farmers in the study include: poor funding, lack of practical understanding of the approach, inadequate access to information on CSAPs, and socio-economic constraints at the farm level.

It would, hence, be recommended that there is a dire need for an aggressive awareness and mobilization campaign for the use of CSAPs as a solution to climate change impact in order to increase farmers' productivity. Additionally, this chapter would also recommend that government and other stakeholders should ensure that productive resources such as land, planting technologies, education and other social amenities be made available and accessible to farmers generally, but more especially women; in order to facilitate easy uptake of climate smart practices. Moreover, there is a need to motivate and encourage farmers to adopt climate smart practices, and one way of achieving this is by incorporating funding devices to support CSAPs and other climate friendly support mechanisms in policy documents.

\section{References}

Adebayo AE, Ojogu EO (2019) Assessment of the use of climate smart agricultural practices among smallholder farmers in Ogun state. Acta Sci Agric 3(6):47-56

Adedeji IA, Tiku NE, Waziri-Ugwu PR, Sanusi SO (2017) The effect of climate change on rice production in Adamawa State, Nigeria. Agroeconomia Croatica 7(1):1-13. ISSN 1333-2422

Adekoya AE, Tologbonse EB (2011) Adoption and diffusion of innovations; agricultural extension in Nigeria, 2nd edn. Agric Exten Soc Niger, Ilorin, pp 36-48

Aderinoye-Abdulwahab SA, Dolapo AT, Matanmi BM, Adisa RS (2016) Ownership of productive resources: a panacea for empowering rural women in Kwara state, Nigeria. J Prod Agric Technol 12(1):17-26

African Climate Smart Agriculture Summit (2014) Twenty-third ordinary session. Equitorial Guinea, Malabo. 26-27 June 2014. http://africacsa.org/introducing-the-africa-csa-allianceascaa/

ECOWAS (2015) A Thematic Roundup of Research, decision-making support and capitalizationextension of endogenous and scientific knowledge for the CSA in the ECOWAS/UEMOA/ CILSS region. Paper prepared for the High Level Forum of Climate-Smart Agriculture (CSA) Stakeholders in West Africa, Bamako, 15-18 June 2015

Ekong EE (2010) An introduction and analysis of rural Nigeria, 3rd edn. Dove Educational Publishers, Uyo, pp 280-266

Fanen T, Olalekan A (2014) Assessing the role of climate-smart agriculture in combating climate change, desertification and improving rural livelihood in Northern Nigeria. Afr J Agric Res 9 (15):1180-1191

FAO (2014) Innovation in family farming. The State of Food and Agriculture Series. A production of Food and Agricultural Organization of the United Nations, Rome. E-ISBN 978-92-5-1085370. Available at: http://www.fao.org/3/a-i4040e.pdf. 161p

FAO (2019). http://www.fao.org/faostat/en/\#data/GT

FAO, ICRISAT (2019a) Climate-smart agriculture in the Adamawa state of Nigeria. CSA Country Profiles for Africa Series. International Center for Tropical Agriculture (CIAT); International Crops Research Institute for the Semi-Arid Tropics (ICRISAT); Food and Agriculture Organization of the United Nations (FAO), Rome. 22p 
FAO, ICRISAT (2019b) Climate-smart agriculture in the Borno state of Nigeria. CSA Country Profiles for Africa Series. International Center for Tropical Agriculture (CIAT); International Crops Research Institute for the Semi-Arid Tropics (ICRISAT); Food and Agriculture Organization of the United Nations (FAO), Rome. 22p

FAO, ICRISAT (2019c) Climate-smart agriculture in the Yobe state of Nigeria. CSA Country Profiles for Africa Series. International Center for Tropical Agriculture (CIAT); International Crops Research Institute for the Semi-Arid Tropics (ICRISAT); Food and Agriculture Organization of the United Nations (FAO), Rome. 22p

Fapojuwo OE, Ogunnaike MG, Shittu AM, Kehinde MO, Oyawole FP (2018) Gender gaps and adoption of climate smart practices among cereal farm households in Nigeria. Niger J Agric Econ 8(1):38-49

Foster V, Briceño-Garmendia C (2010) Africa's infrastructure. A time for transformation. A copublication of the Agence Française de Développement and the World Bank. World Bank, Washington, DC

Ifeanyi-obi CC, Nnadi FN (2014) Climate change adaptation measures used by farmers in SouthSouth Nigeria. J Environ Sci Toxicol Food Technol 8(4):1-6. https://pdfs.semanticscholar.org/ a63d/22bf8b8ebde892a7c9d761ee1653e0e11df6.pdf

IPCC (2012) Managing the risks of extreme events and disasters to advance climate change adaptation. a special report of working groups I and II of the Intergovernmental Panel on Climate Change (eds: Field CB, Barros V, Stocker TF, Qin D, Dokken DJ, Ebi KL, Mastrandrea MD, Mach KJ, Plattner G-K, Allen SK, Tignor M, Midgley PM). Cambridge University Press, Cambridge/New York, $\mathrm{p} 582$

Naswem AA, Akpehe GA, Awuaga MN (2016) Adaptation strategies to climate change among Rice farmers in Katsina-Ala local government area of Benue state, Nigeria. IOSR J Agric Veter Sci 9 (10):33-37

Ojoko EA, Akinwunmi JA, Yusuf SA, Oni OA (2017) Factors influencing the level of use of climate-smart agricultural practices (CSAPs) in Sokoto state, Nigeria. J Agric Sci 62(3):315327

Olorunfemi TO, Olorunfemi OD, Oladele OI (2019) Determinants of the involvement of extension agents in disseminating climate smart agricultural initiatives: implication for scaling up. J Saudi Soc Agric Sci. https://doi.org/10.1016/j.jssas.2019.03.0031-8

Onyeneke RU, Igberi CO, Uwadoka CO, Ogbeni JA (2018) Status of climate-smart agriculture in Southeast Nigeria. GeoJournal 83:333-346. https://doi.org/10.1007/s10708-017-9773-z

Ray GL (2011) Extension communication and management, 8th edn. Kalyani Publishers, New Delhi, pp 147-170

Rogers E (2003) The diffusion of innovations. (5th ed.). New York, NY: The Free Press

Tiamiyu SA, Ugalahi UB, Fabunmi T, Sanusi RO, Fapojuwo EO, Shittu AM (2017) Analysis of farmers' adoption of climate smart agricultural practices in Northern Nigeria. In: Proceedings of the 4th International Conference on Agriculture and Forestry, vol 3, pp 19-26

Tiamiyu SA, Ugalahi UB, Eze JN, Shittu MA (2018a) Adoption of climate smart agricultural practices and farmers' willingness to accept incentives in Nigeria. Int J Agric Environ Res 4 (4):198-205

Tiamiyu SA, Ugalahi UB, Fabunmi T, Sanusi R, Fapojuwo E, Shittu A (2018b) Analysis of farmers' adoption of climate smart agricultural practices in Northern Nigeria, pp 19-26. https://doi.org/ 10.17501/icoaf.2017.3104

USAID (2016) Climate smart agriculture in feed the future programs. Feed THE Future (The U.S. Government's Global Hunger \& Food Security Initiative). Available at: https://www. climatelinks.org/sites/default/files/asset/document/Framework\%20CSA\%20paper\%20final\% $20 \% 281 \% 29$.pdf. $13 p$

Williams TO, Mul M, Cofie O, Kinyangi J, Zougmore R, Wamukoya G, Nyasimi M, Mapfumo P, Speranza CI, Amwata D, Frid-Nielsen S, Partey S, Girvetz E, Rosenstock T, Campbell B (2015) Climate smart agriculture in the African context. Abdou Dlouf international conference center, Feeding Africa an Action Plan for African Agricultural Transformation 
World Bank (2010) Development and climate change. World Development report 2010. World Bank, Washington, DC

World Bank (2018) Scaling up climate-smart agriculture through the Africa climate business plan. World Bank, Washington, DC

Open Access This chapter is licensed under the terms of the Creative Commons Attribution 4.0 International License (http://creativecommons.org/licenses/by/4.0/), which permits use, sharing, adaptation, distribution and reproduction in any medium or format, as long as you give appropriate credit to the original author(s) and the source, provide a link to the Creative Commons license and indicate if changes were made.

The images or other third party material in this chapter are included in the chapter's Creative Commons license, unless indicated otherwise in a credit line to the material. If material is not included in the chapter's Creative Commons license and your intended use is not permitted by statutory regulation or exceeds the permitted use, you will need to obtain permission directly from the copyright holder. 